\title{
Influence of maternal weight gain on birth weight: a gestational diabetes cohort
}

Livia S. Mastella', Letícia S. Weinert', Vanessa Gnielka', Vânia N. Hirakata², Maria Lúcia R. Oppermann ${ }^{3}$, Sandra P. Silveiro ${ }^{1,4}$, Angela J. Reichelt ${ }^{4}$

${ }^{1}$ Programa de Pós-Graduação em Ciências Médicas: Endocrinologia, Universidade Federal do Rio Grande do Sul (UFRGS), Porto Alegre, RS, Brasil 2 Unidade de Bioestatística, Hospital de Clínicas de Porto Alegre (HCPA), Porto Alegre, RS, Brasil ${ }^{3}$ Serviço de Obstetrícia e Ginecologia, Hospital de Clínicas de Porto Alegre (HCPA), Porto Alegre, RS, Brasil ${ }^{4}$ Serviço de Endocrinologia, Hospital de Clínicas de Porto Alegre (HCPA), Porto Alegre, RS, Brasil

Previous presentation: preliminary results presented as abstract/ poster during the Scientific IADPSG Meeting 2016, held in Buenos Aires, Argentina, March 21-23, 2016.

\section{Correspondence to:}

Livia S. Mastella

Rua Ramiro Barcelos, 2350

Prédio 12, 4 andar

90035-003 - Porto Alegre, RS, Brasil

livia_mastella@yahoo.com.br

Received on Sept/11/2016

Accepted on Jun/12/2017

\begin{abstract}
Objective: Our objective was to evaluate gestational weight gain (GWG) patterns and their relation to birth weight. Subjects and methods: We prospectively enrolled 474 women with gestational diabetes mellitus (GDM) at a university hospital (Porto Alegre, Brazil, November 2009-May 2015). GWG was categorized according to the 2009 Institute of Medicine guidelines; birth weight was classified as large (LGA) or small (SGA) for gestational age. Adjusted relative risks (aRRs) and 95\% confidence intervals (95\% Cls) were determined. Results: Adequate GWG occurred in 121 women [25.5\%, 95\% Cl: 22, 30\%]; excessive, in 180 [38.0\%, 95\% Cl: 34, 43\%]; and insufficient, in 173 [36.5\%, 95\% Cl: 32, $41 \%$ ]. In women with normal body mass index (BMI), the prevalence of SGA was higher in those with insufficient compared to adequate GWG $(30 \%$ vs. $0 \%, \mathrm{p}<0.001)$. In women with $\mathrm{BMI} \geq 25 \mathrm{~kg} / \mathrm{m}^{2}$, excessive GWG increased the prevalence of LGA [aRR 2.58, 95\% Cl: $1.06,6.29$ ] and protected from SGA [aRR 0.25, 95\% Cl: 0.10, 0.64]. Insufficient vs. adequate GWG did not influence the prevalence of SGA [aRR 0.61, 95\% Cl: 0.31, 1.22]; insufficient vs. excessive GWG protected from LGA [aRR 0.46, $95 \% \mathrm{Cl}: 0.23,0.91]$. Conclusions: One quarter of this cohort achieved adequate GWG, indicating that specific ranges have to be tailored for GDM. To prevent inadequate birth weight, excessive GWG in women with higher BMI and less than recommended GWG in normal BMI women should be avoided; less than recommended GWG may be suitable for overweight and obese women. Arch Endocrinol Metab. 2018;62(1):48-56
\end{abstract}

\section{Keywords}

Gestational diabetes mellitus; weight gain; birth weight

\section{INTRODUCTION}

G estational diabetes mellitus (GDM) is typically I diagnosed approximately 24-28 weeks using an oral glucose tolerance test (1). Adverse outcomes associated with GDM include increased risk of maternal hypertensive disorders and cesarean section as well as perinatal risks of macrosomia, shoulder dystocia and hypoglycemia (2).

Maternal obesity contributes to GDM and, in an independent fashion, to many other adverse maternal pregnancy outcomes, including pregnancy hypertensive disorders, cesarean section, weight retention, and postpartum diabetes. Adverse outcomes for offspring, including congenital anomalies, macrosomia and indicated preterm delivery, are also increased (3).
Excessive weight gain per se contributes to an increased prevalence of large for gestational age (LGA) and macrosomia (4).

In 2009, the American Institute of Medicine (IOM) updated their recommendations on weight gain in pregnancy without a specific recommendation for GDM (4). Weight gain has been evaluated in several GDM cohort studies, with variable frequencies of adequate, insufficient or excessive weight gain being reported (5-8).

The objectives of this study were to evaluate how the 2009 IOM recommendations on gestational weight gain (GWG) applied to a contemporary cohort of GDM pregnancies and how the patterns of GWG in GDM impacted birth weight. 


\section{SUBJECTS AND METHODS}

We studied a cohort of 508 women with GDM with singleton pregnancies, with at least one prenatal appointment, who delivered at Hospital de Clínicas de Porto Alegre (HCPA), a university hospital. HCPA is located in the Southern state of Brazil, Rio Grande do Sul (population $~ 11$ million inhabitants) and provides medical care through the Sistema Único de Saude (SUS), the national health system. In 2015, more than 600,000 general consultations were performed; approximately 4,000 babies were delivered; and the cesarean rate was 32.8\% (9). From November 2009 to May 2015, all eligible women referred from primary care units were consecutively included; a multidisciplinary team provided prenatal care. Women gave their consent after being fully informed, and the authors signed the confidentiality document for data use. The hospital ethics committee approved the study protocol (number 2010-0364). We followed the STROBE statement for the study report (10).

Thirty-four women were excluded: one due to an abortion, one for having congenital achondroplasia and 32 due to missing data on maternal weight or infant birth weight. GDM was diagnosed with a $75-\mathrm{g}$ oral glucose tolerance test (OGTT) using the criteria of fasting plasma glucose $\geq 110 \mathrm{mg} / \mathrm{dL}$ or 2 -h plasma glucose $\geq 140 \mathrm{mg} / \mathrm{dL}$ in 232 women (49\%) (11). After 2010, the International Association of Diabetes and Pregnancy Study Groups (IADPSG) recommendation was adopted; $242(51 \%)$ of the women met these criteria (12).

Pregestational weight was self-reported, and prepregnancy BMI was classified according to the World Health Organization criteria (13). Weight and height were measured with light clothes and no shoes. All women were prescribed a normocaloric diet, emphasizing the intake of low glycemic index carbohydrates and fiberrich food. Capillary glucose targets were $\leq 95 \mathrm{mg} / \mathrm{dL}$ for pre-meal and $\leq 120 \mathrm{mg} / \mathrm{dL}$ for 2 -h postprandial measures (14). If goals were not met after 2 weeks of nutritional therapy, pharmacological treatment was initiated. Data on pregnancy evolution, delivery, and maternal and newborn outcomes were obtained from hospital registries.

Ethnicity was self-reported. Schooling was categorized as $\leq 11$ years or $>11$ years. Total weight gain was the weight measured at admission to delivery minus the pre-pregnancy weight; weight gains until diagnosis and from diagnosis to delivery were calculated. The 2009 IOM guidance on GWG by BMI was used, including the following ranges: underweight women, 12.5 to $18 \mathrm{~kg}$; normal weight, 11.5 to $16 \mathrm{~kg}$; overweight, 7 to $11 \mathrm{~kg}$ and obese, 5 to $9 \mathrm{~kg}(4)$. An $\mathrm{AlC}$ test was measured at booking (initial AlC test) and during the $3^{\text {rd }}$ trimester $\left(3^{\text {rd }}\right.$ trimester AlC test). Pregnancy-related hypertension disorders included any diagnosis of gestational hypertension or preeclampsia/ eclampsia (15), and the composite of maternal risk factors included hypertensive disorders of pregnancy plus smoking.

Newborns were classified as small for gestational age (SGA) or as LGA according to the Alexander birth weight chart (16), which is routinely used at our hospital. Macrosomia was defined as a term birth weight $\geq 4,000 \mathrm{~g}$, and preterm birth was defined as a delivery before the completion of 37 gestational weeks (17).

Plasma glucose was measured by the enzymatic method and an AlC test using HPLC (Variant II Turbo HbAlC, BioRad Laboratories, Hercules, CA, USA, aligned to DCCT recommendations).

\section{Statistical analysis}

We described the prevalence of adequate gestational weight gain as $\mathrm{n}(\%)$ and evaluated the $95 \%$ confidence intervals [95\% CIs]. Student's t test, $\chi^{2}$ test, ANOVA, and Pearson correlation were applied as appropriate.

Relative risks (RR) and 95\% CIs for SGA and LGA were determined according to maternal weight gain within normal or elevated BMI ranges $\left(\geq 25 \mathrm{~kg} / \mathrm{m}^{2}\right)$. Skin color, living with a partner, schooling, gravidity, weight gain grouped by IOM category, fasting glucose at the time of the diagnostic test, use of pharmacologic treatment, $3^{\text {rd }}$ trimester AlC test, and the composite of maternal risk factors were explored in univariable and multivariable models for SGA. For LGA analysis, we added family history of diabetes to the models. Poisson regression with robust estimation was employed in multivariable analyses. Variables were included if a $\mathrm{p}$ value of at least $<0.10$ was obtained in univariable analysis or if considered clinically important (gravidity and maternal risk factor).

We used SPSS software version 18.8 for statistical analyses. Statistical significance was set at 0.05 , twosided.

\section{RESULTS}

There were some slight differences in baseline clinical characteristics between women classified by the two 
GDM diagnostic criteria (Table 1). We analyzed them as a single group because we assumed that dissimilarities were related to distinct profiles captured by each criterion. The main differences were observed for a family history of diabetes ( $54.3 \%$ vs. $42.6 \%, \mathrm{p}=0.011)$, pregestational BMI $\left(29.4 \pm 6.5\right.$ vs. $30.7 \pm 7.0 \mathrm{~kg} / \mathrm{m}^{2}$, $\mathrm{p}=0.046$ ); the 2 -hour glucose in the diagnostic OGTT $(170.7 \pm 29.1$ vs. $148.5 \pm 37.1 \mathrm{mg} / \mathrm{dL}, \mathrm{p}<0.001)$; the baseline AlC value $(5.7 \% \pm 0.8 \%$ vs. $5.4 \% \pm 0.6 \%$, $\mathrm{p}<0.001$ ), the latter measurement being within the range of laboratory references $(6.0 \%)$; and weight at delivery $(84.0 \pm 17.3$ vs. $89.1 \pm 18.5 \mathrm{~kg}, \mathrm{p}=0.002)$. No differences were found regarding key maternal and perinatal outcomes.

Among the 474 women, only one had a BMI $<18.5$ $\mathrm{kg} / \mathrm{m}^{2}$, and this case was analyzed in the normal BMI group; 119 had normal BMIs ( $\mathrm{n}=120,25 \%, 95 \% \mathrm{CI}$ : $21,29 \%)$; and 354 (75\%, 95\% CI: 71, 79\%) had BMIs $\geq 25 \mathrm{~kg} / \mathrm{m}^{2}$. Adequate weight gain occurred in 121 women [25.5\%, 95\% CI: 22, 30\%], excessive in 180

Table 1. Comparison of women with gestational diabetes according to two diagnostic criteria

\begin{tabular}{|c|c|c|c|}
\hline \multirow[t]{2}{*}{ Characteristic/outcome } & $\begin{array}{c}\text { Brazilian criteria } \\
\mathrm{N}=232\end{array}$ & $\begin{array}{l}\text { IADPSG criteria } \\
\mathrm{N}=242\end{array}$ & \multirow[t]{2}{*}{ p } \\
\hline & Mean \pm SD or $\%$ & Mean \pm SD or $\%$ & \\
\hline \multicolumn{4}{|l|}{ Maternal } \\
\hline Age (years) & $31.4 \pm 6.2$ & $31.2 \pm 6.7$ & 0.755 \\
\hline White ethnicity & 75.4 & 78.9 & 0.365 \\
\hline Education (> 11 years) & 49.6 & 47.5 & 0.656 \\
\hline With partner & 63.4 & 45.5 & $<0.001$ \\
\hline Pregnancies (n) & $2.7 \pm 1.6$ & $2.8 \pm 1.7$ & 0.789 \\
\hline Current smoker & 0.9 & 3.3 & 0.064 \\
\hline Family history of diabetes & 54.3 & 42.6 & 0.011 \\
\hline Previous GDM & 13.4 & 13.2 & 0.964 \\
\hline Pre-pregnancy BMI (kg/m²) & $29.4 \pm 6.5$ & $30.7 \pm 7.0$ & 0.046 \\
\hline Systolic BP (mmHg) & $115.8 \pm 11.9$ & $117.0 \pm 12.3$ & 0.287 \\
\hline Diastolic BP (mmHg) & $72.5 \pm 10.2$ & $73.0 \pm 9.8$ & 0.591 \\
\hline \multicolumn{4}{|l|}{ Glycemia in the OGTT $(\mathrm{mg} / \mathrm{dL})^{\star *}$} \\
\hline Fasting & $100.0 \pm 27$ & $97.2 \pm 16.4$ & 0.177 \\
\hline 1 hour $(n=180)$ & - & $178.4 \pm 35.8$ & - \\
\hline 2 hour & $\begin{array}{c}170.7 \pm 29.1 \\
n=226\end{array}$ & $\begin{array}{c}148.5 \pm 37.1 \\
n=200\end{array}$ & $<0.001$ \\
\hline $2^{\text {nd }}$ trimester $\mathrm{A} 1 \mathrm{C}$ test $(\%)^{\star \star \star}$ & $5.7 \pm 0.8$ & $5.4 \pm 0.6$ & $<0.001$ \\
\hline $3^{\text {rd }}$ trimester weight gain $(\mathrm{kg})$ & $2.0 \pm 4.0$ & $2.7 \pm 4.2$ & 0.066 \\
\hline Weight at delivery (kg) & $84.0 \pm 17.3$ & $89.1 \pm 18.5$ & 0.002 \\
\hline Total gestational weight gain (kg) & $10.5 \pm 7.5$ & $10.1 \pm 7.9$ & 0.598 \\
\hline Hypertensive disorders of pregnancy & 13.8 & 12.0 & 0.556 \\
\hline Cesarean section & 58.6 & 52.1 & 0.151 \\
\hline \multicolumn{4}{|l|}{ Offspring } \\
\hline Birth weight (g) & $3,221.6 \pm 578.7$ & $3,246.6 \pm 602.8$ & 0.645 \\
\hline Birth weight category & & & 0.681 \\
\hline SGA & 9.9 & 12.0 & \\
\hline AGA & 78.9 & 75.6 & \\
\hline LGA & 11.2 & 12.4 & \\
\hline Macrosomia & 7.3 & 8.3 & 0.704 \\
\hline
\end{tabular}

IADPSG: International Association of Diabetes in Pregnancy Study Groups; GDM: gestational diabetes mellitus; BMl: body mass index; BP: blood pressure; OGT: oral glucose tolerance test; SGA small for gestational age; AGA: adequate for gestational age; LGA: large for gestational age.

${ }^{*} n=230$ for the Brazilian criteria and 241 for the IADPSG criteria; ${ }^{* \star} n=226$ for the Brazilian criteria and 200 for the IADPSG criteria; ${ }^{\star \star \star} n=206$ for the Brazilian criteria and 207 for the IADPSG criteria. 
[38\%, 95\% CI: $34,43 \%$ ] and insufficient in 173 [36.5\%, 95\% CI: 32, 41\%]. Pre-pregnancy hypertension was present in $12.4 \%$ of the women, and preeclampsia/ gestational hypertension was present in $9.5 \%$ of the women. The average gestational age at delivery was $38 \pm 1.5$ weeks (range: $30-41$ weeks), and the rate of cesarean section was $55.3 \%$. The baseline characteristics of the 474 women according to gestational weight gain categories are presented in Table 2.

When demographic and social characteristics across GWG categories (insufficient vs. adequate vs. excessive) were analyzed, maternal age was higher in women with insufficient GWG compared to those with excessive gain (Table 2). Fasting plasma glucose (mg/dL) in the OGTT was available for all women ( $98 \pm 18$ vs. $98 \pm 26$ vs. $100 \pm$ $23, \mathrm{p}=0.455)$, 1 h glucose was available for 180 women $(182 \pm 35$ vs. $185 \pm 38$ vs. $171 \pm 34, \mathrm{p}=0.104)$ and $2 \mathrm{~h}$ glucose was available for 426 women $(162 \pm 31$ vs. 162 \pm 40 vs. $158 \pm 35, \mathrm{p}=0.558$ ). The initial AlC level was measured in 413 women at a mean gestational age of 31 \pm 5.8 weeks and was similar across groups $(5.6 \% \pm 0.7 \%$ vs. $5.5 \% \pm 0.8 \%$ vs. $5.7 \% \pm 0.8 \%, \mathrm{p}=0.070)$.

Women who gained insufficient weight were more likely to be receiving pharmacological treatment (insulin or oral agents) compared to those with adequate gain ( $58 \%$ vs. $40 \%, \mathrm{p}=0.009)$. Metformin treatment was less frequent in those with adequate weight gain $(31 \%)$ compared to those with insufficient weight gain $(47 \%$, $\mathrm{p}=0.023$ ), but in the excessive weight gain group
(42\%), the rates were not different compared to the two other groups. Insulin use was similar across all three groups ( $19.0 \%$ vs. $13.2 \%$ vs. $16.1 \%, \mathrm{p}=0.407)$.

The primary data on maternal weight gain by IOM category for the two BMI groups (normal and overweight/obese) are displayed in Table 3. Total weight gain increased significantly across the groups. Weight at delivery increased significantly across the three IOM categories in normal BMI women $(63.3 \pm 6.4$ vs. $69.9 \pm 6.7$ vs. $80.7 \pm 7.3 \mathrm{~kg}, \mathrm{p}=0.001)$. In women with BMI $\geq 25 \mathrm{~kg} / \mathrm{m}^{2}$, the average weight gain was almost $10 \mathrm{~kg}$ higher in the excessive weight gain group.

Table 3 depicts offspring outcomes according to GWG categories. The mean \pm SD birth weight was $3.234 \pm 591 \mathrm{~g} ; 242(51 \%)$ newborns were male; 52 (11\%) were SGA and 56 (12\%) LGA; and $37(7.8 \%)$ were macrosomic. The preterm birth rate was $16.5 \%$ and was similar across groups (insufficient, 20\%, adequate, $13 \%$ and excessive, $16 \%, \mathrm{p}=0.315$ ).

The Pearson correlation ( $r$ ) between GWG and birth weight in normal BMI women was weak, 0.47 $(\mathrm{p}<0.001)$, with a coefficient of determination $\left(\mathrm{r}^{2}\right)$ of 0.22 ; in the group with overweight/obesity, $\mathrm{r}$ was lower, $0.24(\mathrm{p}<0.001)$, and $\mathrm{r}^{2}$ was 0.06 . The overall $\mathrm{r}$ coefficient was $0.26(\mathrm{p}<0.001)$, and $\mathrm{r}^{2}$ was 0.07 .

We could not run univariable analyses in the normal BMI group due to the lack of SGA babies and the presence of only one LGA baby in the adequate gain category (Table 3). Pharmacological treatment,

Table 2. Baseline characteristics of 474 women with gestational diabetes according to the 2009 Institute of Medicine weight gain categories

\begin{tabular}{|c|c|c|c|c|c|}
\hline \multirow[b]{2}{*}{ Characteristic } & \multicolumn{4}{|c|}{ Weight gain category } & \multirow[b]{2}{*}{$\mathrm{p}$ value } \\
\hline & $\begin{array}{c}\text { Total } \\
\mathrm{n}=474\end{array}$ & $\begin{array}{c}\text { Insufficient } \\
\mathrm{n}=173(36.5)\end{array}$ & $\begin{array}{c}\text { Adequate } \\
\mathrm{n}=121(25.5)\end{array}$ & $\begin{array}{c}\text { Excessive } \\
\mathrm{n}=180(38)\end{array}$ & \\
\hline Age (years)\& & $31 \pm 6.4$ & $33 \pm 6.0$ & $31 \pm 6.6$ & $30 \pm 6.5$ & 0.001 \\
\hline White ethnicity & $366(77)$ & $138(80)$ & $99(82)$ & $129(72)$ & 0.073 \\
\hline Education, $>11$ years & $230(49)$ & $84(49)$ & $57(47)$ & $89(49)$ & 0.924 \\
\hline With partner & $257(54)$ & $101(58)$ & $67(55)$ & $89(49)$ & 0.232 \\
\hline Pregnancies (n) & $2.7 \pm 1.7$ & $2.8 \pm 1.6$ & $2.9 \pm 1.6$ & $2.6 \pm 1.7$ & 0.347 \\
\hline Current smoker & $10(2)$ & $4(2.3)$ & $2(1.7)$ & $4(2.2)$ & 0.920 \\
\hline Family history of diabetes & $229(48)$ & $74(43)$ & $63(52)$ & $92(51)$ & 0.185 \\
\hline Previous GDM & $63(13)$ & $26(15)$ & $15(12)$ & $22(12)$ & 0.699 \\
\hline Pre-pregnancy BMI (kg/m²) & $30.1 \pm 6.8$ & $30.7 \pm 7.8$ & $29.2 \pm 6.5$ & $29.9 \pm 5.8$ & 0.194 \\
\hline Systolic BP (mmHg), $n=471$ & $116 \pm 12$ & $115 \pm 13$ & $116 \pm 12$ & $118 \pm 12$ & 0.120 \\
\hline Diastolic BP (mmHg), $n=471$ & $73 \pm 10$ & $73 \pm 10$ & $71 \pm 9$ & $74 \pm 11$ & 0.163 \\
\hline
\end{tabular}

GDM: gestational diabetes mellitus; BMl: body mass index; BP: blood pressure.

Data represent the mean \pm standard deviation (SD) or $\mathrm{n}(\%)$. ANOVA and Tukey's test for multiple comparisons $\chi^{2}$ test and $\mathrm{Z}$ test for proportion with Bonferroni adjustment.

\& Insufficient and excessive groups are significantly different. 
excessive total GWG and excessive gain in the $3^{\text {rd }}$ trimester were all statistically significant in the BMI $\geq$ $25 \mathrm{~kg} / \mathrm{m}^{2}$ group and were included in the multivariable model, as were gravidity and $3^{\text {rd }}$ trimester AlC. A maternal risk factor composite was added to SGA model, and the fasting plasma glucose at the OGTT was added to the LGA model.

Analyses were run including the total GWG and $3^{\text {rd }}$ trimester gain separately, with adequate weight gain as the reference category. Comparisons of the effect of insufficient GWG on LGA risk were also performed, with excessive GWG as reference. Overall, we analyzed 328 pregnancies with 34 SGA and 42 LGA infants in multivariable models.

As observed in Table 4, the SGA risk decreased 75\% with excessive total GWG and 23\% with each kilogram gained during the third trimester but was not enhanced by insufficient weight gain. The LGA risk increased independently with total GWG; each kilogram gained in the $3^{\text {rd }}$ trimester increased the risk by $10 \%$. In

Table 3. Pregnancy outcomes according to pre-pregnancy body mass index and 2009 Institute of Medicine weight gain categories in 474 women with gestational diabetes

\begin{tabular}{|c|c|c|c|c|}
\hline \multirow{2}{*}{ Outcome according to BMI } & \multicolumn{3}{|c|}{ Weight gain category } & \multirow{2}{*}{$\mathrm{p}$ value } \\
\hline & Insufficient & Adequate & Excessive & \\
\hline $\mathrm{BMI}<25 \mathrm{~kg} / \mathrm{m}^{2}(\mathrm{n}=120)$ & $\mathrm{n}=54$ & $\mathrm{n}=34$ & $\mathrm{n}=32$ & \\
\hline \multicolumn{5}{|l|}{ Maternal } \\
\hline $3^{\text {rd }}$ trimester weight gain ${ }^{*}$ & $-0.7 \pm 4.6$ & $2.4 \pm 2.3$ & $4.1 \pm 5.3$ & $<0.001$ \\
\hline Weight at delivery $(\mathrm{kg})^{n}$ & $63.3 \pm 6.4$ & $69.9 \pm 6.7$ & $80.7 \pm 7.3$ & $<0.001$ \\
\hline Total weight gain $(\mathrm{kg})^{\Re}$ & $6.8 \pm 3.0$ & $13.3 \pm 1.3$ & $22.6 \pm 5.0$ & $<0.001$ \\
\hline Hypertensive disorders of pregnancy & $7(13)$ & $2(6)$ & $2(6)$ & 0.427 \\
\hline Cesarean section & $24(44)$ & $18(53)$ & $16(50)$ & 0.722 \\
\hline Maternal risk factors & $12(22)$ & $2(6)$ & $4(13)$ & 0.101 \\
\hline \multicolumn{5}{|l|}{ Offspring } \\
\hline Birth weight (g)\# & $2868 \pm 478$ & $3284 \pm 368$ & $3413 \pm 454$ & $<0.001$ \\
\hline Birth weight category & & & & $<0.001$ \\
\hline $\mathrm{SGA}^{\#}$ & $16(30)$ & $0(0)$ & $1(3)$ & \\
\hline$A G A^{\varepsilon}$ & $37(69)$ & $33(97)$ & $25(78)$ & \\
\hline$L G A^{\&}$ & $1(2)$ & $1(3)$ & $6(19)$ & \\
\hline $\mathrm{BMI} \geq 25 \mathrm{~kg} / \mathrm{m}^{2}(\mathrm{n}=354)$ & $n=119$ & $\mathrm{n}=87$ & $n=148$ & \\
\hline \multicolumn{5}{|l|}{ Maternal } \\
\hline $3^{\text {rd }}$ trimester weight gain? & $0.7 \pm 2.8$ & $2.2 \pm 3.4$ & $4.1 \pm 4.3$ & $<0.001$ \\
\hline Weight at delivery $(\mathrm{kg})^{\dagger}$ & $88.0 \pm 18.0$ & $88 \pm 16.0$ & $98 \pm 14$ & $<0.001$ \\
\hline Total weight gain $(\mathrm{kg})^{\Uparrow}$ & $1.8 \pm 3.1$ & $8.2 \pm 1.8$ & $16.4 \pm 5.8$ & $<0.001$ \\
\hline Hypertensive disorders of pregnancy & $11(9)$ & $12(14)$ & $27(18)$ & 0.110 \\
\hline Cesarean section & $66(56)$ & $49(56)$ & $89(60)$ & 0.715 \\
\hline Maternal risk factors* & $35(29)$ & $23(26)$ & $43(29)$ & 0.882 \\
\hline \multicolumn{5}{|l|}{ Offspring } \\
\hline Birth weight $(\mathrm{g})^{\dagger}$ & $3157 \pm 642$ & $3157 \pm 569$ & $3425 \pm 586$ & $<0.001$ \\
\hline Birth weight category & & & & $<0.001$ \\
\hline $\mathrm{SGA}^{\S}$ & $12(10)$ & $17(20)$ & $6(4)$ & \\
\hline AGA & $94(79)$ & $64(74)$ & $113(76)$ & \\
\hline$L G A^{\S}$ & $13(11)$ & $6(7)$ & $29(20)$ & \\
\hline
\end{tabular}

${ }^{*}$ Maternal risk factors include: hypertensive disorders of pregnancy plus smoking.

BMI: body mass index; n: number; SGA: small for gestational age; AGA: adequate for gestational age; LGA: large for gestational age. Data represent the mean \pm standard deviation $(\mathrm{SD})$ or $\mathrm{n}(\%)$.

ANOVA and Tukey's test for multiple comparisons $\chi^{2}$ test and $Z$ test for proportion with Bonferroni adjustment.

\# insufficient group is significantly different from the adequate or excessive groups; ${ }^{\circledR}$ insufficient and adequate groups were different; \& insufficient and excessive groups were different; ${ }^{\dagger}$ insufficient and adequate groups were different from the excessive group; ${ }^{\circledR}$ all groups were different; ${ }^{\S}$ adequate and excessive groups were different. 
addition to weight gain, pharmacological treatment increased the LGA risk in the model with total GWG (RR 2.60, 95\% CI: $1.11,5.81$ ). In the model with $3^{\text {rd }}$ trimester weight gain, the risks were also independently increased with pharmacological treatment (RR 2.38; 95\% CI: $1.10,5.28)$ and $3^{\text {rd }}$ trimester AlC (RR 1.72; 95\% CI: $1.28,2.31)$. Both adequate and insufficient weight gain had a protective effect upon LGA risk when compared to excessive weight gain.

Table 4. Risk for small and large for gestational age babies in women with gestational diabetes with $\mathrm{BMl} \geq 25 \mathrm{~kg} / \mathrm{m}^{2}$ according to gestational weight gain

\begin{tabular}{|c|c|c|}
\hline \multirow{2}{*}{ Risk factor } & \multicolumn{2}{|c|}{ Multivariable analysis* } \\
\hline & aRR $[95 \% \mathrm{Cl}]$ & $\mathrm{p}$ value \\
\hline & \multicolumn{2}{|c|}{ Small for gestational age } \\
\hline \multicolumn{3}{|c|}{ Total GWG (adequate as reference) } \\
\hline Excessive & $0.25[0.10,0.64]$ & $0.004^{\mathrm{a}}$ \\
\hline Insufficient & $0.61[0.31,1.22]$ & 0.161 \\
\hline \multirow[t]{2}{*}{$3^{\text {rd }}$ trimester weight gain $(\mathrm{kg})$} & $0.87[0.81,0.95]$ & $0.001^{\mathrm{a}}$ \\
\hline & \multicolumn{2}{|c|}{ Large for gestational age } \\
\hline \multicolumn{3}{|c|}{ Total GWG (adequate as reference) } \\
\hline Excessive & $2.58[1.06,6.29]$ & $0.037^{b}$ \\
\hline Insufficient & $1.17[0.42,3.29]$ & 0.768 \\
\hline $3^{\text {rd }}$ trimester weight gain $(\mathrm{kg})$ & $1.11[1.05,1.17]$ & $<0.001^{b}$ \\
\hline \multicolumn{3}{|c|}{ Total GWG (excessive as reference) } \\
\hline Adequate & $0.39[0.16,0.95]$ & $0.037^{b}$ \\
\hline Insufficient & $0.46[0.23,0.91]$ & 0.026 \\
\hline
\end{tabular}

aRR [95\% Cl]: adjusted relative risk (95\% confidence interval); GWG: gestational weight gain. * Poisson regression with robust estimation.

a Adjusted for gravidity, pharmacological treatment, maternal risk factors, and $3^{\text {rd }}$ trimester A1C.

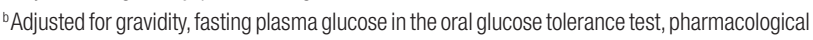
treatment, and $3^{\text {rd }}$ trimester $\mathrm{A} 1 \mathrm{C}$

\section{COMMENTS}

In this GDM cohort, adequate weight gain was attained by only one quarter of women. Those with normal BMI had increased SGA rates with insufficient weight gain. In women with overweight or obesity, excessive GWG increased the LGA risk and protected from SGA, while there was a trend towards a decreased risk of LGA when GWG was insufficient.

Overweight and obesity were frequent in our cohort $(75 \%)$, with a rate quite similar to that described for type 2 diabetes pregnancies, $80 \%$ (18), reflecting the pattern described in $49.1 \%$ of non-pregnant Brazilian women in a recent survey (19). Variable rates of obesity, 17 to $71 \%$, have been reported in GDM cohorts; different study populations and diagnostic criteria may explain this wide range $(5-7,20,21)$. Maternal and offspring outcomes can be worsened if women enter pregnancy in the overweight or obese categories; deleterious effects are further magnified by excessive weight gain (22). The high frequency of excessive GWG found (38\%) was expected, since up to $65 \%$ women were reported gaining more weight than recommended in several cohort studies in $\operatorname{GDM}(5,7,8,22)$. This is not exclusive to GDM pregnancies; a similar rate $(32.9 \%)$ was observed in women in a large Brazilian cohort $(\mathrm{n}=2,244)$ (23). Less than recommended GWG was $33.4 \%$ in the latter cohort, close to our rate $(36.5 \%)$ and to those described in GDM (up to $40 \%$ of women) $(7,8)$. The influence of GWG on GDM outcomes may therefore be uncertain, leading to the conclusion by a National Institutes of Health committee that evidence was insufficient "because of inconsistency across studies and imprecise effect estimates" (24).

We observed higher weight gain until GDM diagnosis followed by lower gain thereafter, as described in other studies $(25,26)$; this reinforces the idea that more than intervention per se, being labeled GDM may increase treatment compliance (27). Moreover, we suppose that excessive weight might be perceived as deleterious by GDM mothers, since overweight and obese women gained approximately $5 \mathrm{~kg}$ less than their normal BMI counterparts along pregnancy. Women with insufficient weight gain in our cohort frequently needed pharmacological treatment; this association was also found in the Atlantic-DIP cohort, where insulin use was common in women with lower weight gain (5), in contrast to what was previously described (25). A possible explanation could be the presence of a more severe degree of metabolic disorder. We could not further explore this possibility because we did not measure insulin or C-peptide. We can speculate that this may in part also explain the interesting finding that women gaining insufficient weight were older than those with excessive weight gain. Another explanation for this latter finding could be ascribed to the presence of some degree of placental insufficiency in the oldest group or to compliance being greater due to their previous life experiences.

Although excessive and insufficient weight gain were frequent, maternal outcomes seemed unaffected in our study, opposing findings described by other authors: a higher weight gain in GDM pregnancies increased risks of cesarean section $(7,22)$ and pregnancy-related 
hypertension by almost two-fold in Irish women with excessive weight gain (5).

Regarding offspring outcomes, we found that only $7 \%$ of birth weight could be explained by maternal GWG. Despite this, normal BMI women who gained less than the recommended GWG delivered more SGA babies, while in overweight/obese women we did not observe this association. Furthermore, the SGA rate was close to that of the LGA rate for the whole group, an unexpected finding. We could speculate that close surveillance of diet and weight gain could eventually be an explanation for both an increased rate of SGA in normal BMI women and a decreased rate of LGA in women with adequate or insufficient weight gain, while in women with excessive GWG, high rates of LGA remained. In non-diabetic pregnancies, delivery of SGA or low birth weight babies $(<2,500 \mathrm{~g})$ is associated with multiple factors, such as hypertension, smoking and insufficient weight gain (27). No difference in hypertension or smoking rates across the weight gain groups was found. High rates of SGA were not expected, as it is well established that GDM treatment per se does not increase this risk (28). However, 22\% of birth weight was ascribed to GWG in normal BMI women in our study, which could partially explain our findings. Weight gain below recommendations was not related to increased rates of SGA in other GDM cohorts $(8,25)$ nor was it in a type 2 diabetes cohort $(18)$; of note, the results were not adjusted by pre-pregnancy BMI categories. Weight loss in GDM women with BMI $\geq 25 \mathrm{~kg} / \mathrm{m}^{2}$ resulted in increased SGA in a large American cohort, despite protecting against LGA and macrosomia, although in the study, the last weight measurement was taken around a mean gestational age of 34.8 weeks (29). The linkage between SGA and poor maternal weight gain, which is stronger in underweight women, is not well established yet for other BMI categories in non-GDM pregnancies and not even in GDM, though it is described in large cohort studies and remains positive when adjusted for confounders such as smoking and hypertension (4). It is tempting to speculate that other factors such as vitamin D deficiency might play a role. Maternal vitamin D deficiency and an increased rate of SGA births have been previously described in our cohort (30).

Excessive birth weight is conditioned by maternal obesity and hyperglycemia as well as by excessive weight gain $(21,31,32)$. The association of birth weight with maternal weight gain has been described in women with type 2 diabetes (18), in obese-only women (31), and in obese GDM women (33), reflecting the independent role of those factors. Gestational diabetes leads to excessive birth weight irrespective of diagnostic criteria (2), while proper treatment has been associated with decreased risk (28). In our cohort, as in others, higher rates of LGA were associated with excessive weight gain mainly in overweight and obese women $(7,8,25)$. In the Atlantic-DIP cohort, adjusted risks of similar magnitude to ours were reported for LGA (5), while in another cohort, LGA was increased in obese, but not in overweight, women (6). It is worthy of consideration that those studies calculated GWG from the time of booking. The independent effects of hyperglycemia and weight gain on birth weight were recently quantified: an AlC test $<5.0 \%$ avoided $47 \%$ of LGA, while adequate GWG avoided 52\% of LGA (32). Finally, total GWG was not the only important factor in our study; weight gain in the third trimester also independently influenced LGA risk. A trend towards LGA risk was previously reported in women with excessive GWG after GDM diagnosis (34).

Insufficient GWG and its influence on LGA have been less commonly evaluated. A tendency toward a decreased LGA risk was previously reported in obese GDM women, as well as in overweight women (aRR $1.05,95 \%$ CI: $0.68,4.19)$, with a risk magnitude similar to ours (aRR 1.17 (95\% CI: 0.42, 3.29) (6). The protective effect of lower GWG on LGA risk compared to excessive gaining was expected, as we compared two extremes, but it is worth saying that women with insufficient GWG had a trend toward delivering more LGA babies than those gaining adequate weight. We believe that the independent effects of hyperglycemia and increased BMI could prevail over that of GWG because their additive effects, which are mediated through maternal hyperlipidemia and relative insulin insufficiency, further stimulate insulin secretion by the fetal pancreas, promoting intrauterine overgrowth (21). Appropriate treatment strategies, including reduced weight gain, potentially counteract these metabolic effects (35).

The main strength of our study is the possibility to evaluate the 2009 IOM recommendation on GWG in a mixed ethnic cohort with a typical GDM profile of excessive BMI at the beginning of pregnancy. In addition to the well-known effects of excessive GWG, we demonstrated that less than recommended GWG might not be deleterious in GDM pregnancies. 
A study limitation, the influence of treatment on pregnancy outcomes, is inherent to the study design and is mitigated by the similar antenatal care offered throughout the time period.

In conclusion, only one quarter of this cohort achieved weight gain within the 2009 IOM guidance, perhaps indicating that specific ranges should be tailored for GDM pregnancies. Less than currently recommended GWG should be avoided in normal BMI women, although it may be suitable for overweight and obese women because it prevents excessive birth weight. Excessive GWG should be prevented in overweight and obese women to reduce the risk of large for gestational age babies.

Author's contributions: LSM, SPS and AJR designed research; LSM, LSW and VG conducted research; VNH and AJR performed statistical analysis; MLRO, SPS and AJR contributed to discussion, wrote the manuscript and are responsible for the final content. All authors revised the manuscript.

Acknowledgments: the authors acknowledge Professors Maria Inês Schmidt, Michele Drehmer and Themis Zelmanovitz, from Universidade Federal do Rio Grande do Sul (UFRGS), Porto Alegre, Brazil, for useful suggestions; Natália Jaeger for helping with language review and Scientific Linguagem Ltda. for manuscript preparation.

Financial disclosure: fund for Research and Event Promotion, Hospital de Clínicas de Porto Alegre (FIPE-HCPA).

Disclosure: no potential conflict of interest relevant to this article was reported.

\section{REFERENCES}

1. World Health Organization. WHO Guidelines Approved by the Guidelines Review Committee. Diagnostic criteria and classification of hyperglycemia first detected in pregnancy. Geneva: World Health Organization Copyright; 2013.

2. Wendland EM, Torloni MR, Falavigna M, Trujillo J, Dode MA, Campos MA, et al. Gestational diabetes and pregnancy outcomes - A systematic review of the World Health Organization (WHO) and the International Association of Diabetes in Pregnancy Study Groups (IADPSG) diagnostic criteria. BMC Pregnancy Childbirth. 2012 Mar 31;12:23.

3. Yogev Y, Catalano PM. Pregnancy and obesity. Obstet Gynecol Clin North Am. 2009;36(2):285-300, viii.

4. Institute of Medicine and National Research Council Committee to Reexamine (IOMPWG). The National Academies Collection: Reports funded by National Institutes of Health. Washington: National Academies Press; 2009.

5. Egan AM, Dennedy MC, Al-Ramli W, Heerey A, Avalos G, Dunne F. ATLANTIC-DIP: excessive gestational weight gain and pregnancy outcomes in women with gestational or pregestational diabetes mellitus. J Clin Endocrinol Metabol. 2014;99(1):212-9.
6. Berggren EK, Stuebe AM, Boggess KA. Excess Maternal Weight Gain and Large for Gestational Age Risk among Women with Gestational Diabetes. Am J Perinatol. 2015;32(3):251-6.

7. Horosz E, Bomba-Opon DA, Szymanska M, Wielgos M. Maternal weight gain in women with gestational diabetes mellitus. J Perinat Med. 2013;41(5):523-8.

8. Wong VW, Russell H. Weight gain during pregnancy in women with gestational diabetes: How little is too little? Diabetes Res Clin Pract. 2013;102(2):e32-4.

9. Hospital de Clínicas de Porto Alegre. Relatório de Gestão do Exercício de 2015-2016 [2016 Nov 01]. Available from: http://https:// www.hcpa.edu.br/downloads/ccom/inst_gestao_publicacoes/ relatorio_de_2015.pdf.

10. von Elm E, Altman DG, Egger M, Pocock SJ, Gotzsche PC, Vandenbroucke JP, et al. The Strengthening the Reporting of Observational Studies in Epidemiology (STROBE) statement: guidelines for reporting observational studies. Lancet. 2007;370(9596):1453-7.

11. Reichelt AAJ, Oppermann MLR, Schmidt MI. [Guidelines of the 2nd Meeting of the diabetes and pregnancy task force]. Arq Bras Endocrinol Metab. 2002;46(5):574-81.

12. International Association of $D$, Pregnancy Study Groups Consensus P, Metzger BE, Gabbe SG, Persson B, Buchanan TA, Catalano PA, Damm P, et al. International association of diabetes and pregnancy study groups recommendations on the diagnosis and classification of hyperglycemia in pregnancy. Diabetes Care. 2010;33(3):676-82.

13. World Health Organization. Physical status: the use and interpretation of anthropometry. Report of a WHO Expert Committee. 1995;854:435-45.

14. Weinert LS, Silveiro SP, Oppermann ML, Salazar CC, Simionato BM, Siebeneichler A, et al. [Gestational diabetes management: a multidisciplinary treatment algorithm]. Arq Bras Endocrinol Metab. 2011;55(7):435-45.

15. Tranquilli AL, Dekker G, Magee L, Roberts J, Sibai BM, Steyn W, et al. The classification, diagnosis and management of the hypertensive disorders of pregnancy: a revised statement from the ISSHP. Pregnancy Hypertens. 2014;4(2):97-104.

16. Alexander GR, Himes JH, Kaufman RB, Mor J, Kogan M. A United States national reference for fetal growth. Obstet Gynecol. 1996;87(2):163-8.

17. International Association of Diabetes in Pregnancy Study Group Working Group on Outcome D, Feig DS, Corcoy R, Jensen DM, Kautzky-Willer A, Nolan CJ, Oats JJ, et al. Diabetes in pregnancy outcomes: a systematic review and proposed codification of definitions. Diabetes Metab Res Rev. 2015;31(7):680-90.

18. Parellada CB, Asbjornsdottir B, Ringholm L, Damm P, Mathiesen ER. Fetal growth in relation to gestational weight gain in women with type 2 diabetes: an observational study. Diabet Med. 2014;31(12):1681-9.

19. Brasil. Ministério da Saúde. Vigitel: Vigilância de fatores de risco e proteção para doenças crônicas por inquérito telefônico 2014. Brasília; 2014. Available from: http://portalsaude.saude.gov.br/images/pdf/2015/abril/15/PPT-Vigitel-2014-.pdf.

20. Kase BA, Cormier CM, Costantine MM, Hutchinson M, Ramin SM, Saade GR, et al. Excessive gestational weight gain in women with gestational and pregestational diabetes. Am J Perinatol. 2011;28(10):761-6.

21. Catalano PM, Mclntyre HD, Cruickshank JK, McCance DR, Dyer $A R$, Metzger BE, et al. The hyperglycemia and adverse pregnancy outcome study: associations of GDM and obesity with pregnancy outcomes. Diabetes Care. 2012;35(4):780-6.

22. Ouzounian JG, Hernandez GD, Korst LM, Montoro MM, Battista $\mathrm{LR}$, Walden $\mathrm{CL}$, et al. Pre-pregnancy weight and excess weight gain are risk factors for macrosomia in women with gestational diabetes. J Perinatol. 2011;31(11):717-21. 
23. Drehmer M, Duncan BB, Kac G, Schmidt MI. Association of second and third trimester weight gain in pregnancy with maternal and fetal outcomes. PloS One. 2013;8(1):e54704.

24. Hartling L, Dryden DM, Guthrie A, Muise M, Vandermeer B, Donovan L. Benefits and harms of treating gestational diabetes mellitus: a systematic review and meta-analysis for the U.S. Preventive Services Task Force and the National Institutes of Health Office of Medical Applications of Research. Ann Intern Med. 2013;159(2):123-9.

25. Park JE, Park S, Daily JW, Kim SH. Low gestational weight gain improves infant and maternal pregnancy outcomes in overweight and obese Korean women with gestational diabetes mellitus. Gynecol Endocrinol. 2011;27(10):775-81.

26. Stewart ZA, Wallace EM, Allan CA. Patterns of weight gain in pregnant women with and without gestational diabetes mellitus: an observational study. Aust N Z J Obstet Gynaecol. 2012;52(5):433-9.

27. Han Z, Lutsiv O, Mulla S, Rosen A, Beyene J, McDonald SD, et al. Low gestational weight gain and the risk of preterm birth and low birthweight: a systematic review and meta-analyses. Acta Obstet Gynecol Scand. 2011;90(9):935-54.

28. Falavigna M, Schmidt MI, Trujillo J, Alves LF, Wendland ER, TorIoni MR, et al. Effectiveness of gestational diabetes treatment: a systematic review with quality of evidence assessment. Diabetes Res Clin Pract. 2012;98(3):396-405.
29. Yee LM, Cheng YW, Inturrisi M, Caughey AB. Gestational weight loss and perinatal outcomes in overweight and obese women subsequent to diagnosis of gestational diabetes mellitus. Obesity. 2013;21(12):E770-4.

30. Weinert LS, Silveiro SP. Maternal-fetal impact of vitamin D deficiency: a critical review. Matern Child Health J. 2015;19(1):94-101.

31. Gavard JA, Artal R. The association of gestational weight gain with birth weight in obese pregnant women by obesity class and diabetic status: a population-based historical cohort study. Matern Child Health J. 2014;18(4):1038-47.

32. Barquiel B, Herranz L, Hillman N, Burgos MA, Grande C, Tukia $\mathrm{KM}$, et al. HbA1c and Gestational Weight Gain Are Factors that Influence Neonatal Outcome in Mothers with Gestational Diabetes. J Womens Health. 2016;25(6):579-85.

33. Gante I, Amaral N, Dores J, Almeida MC. Impact of gestational weight gain on obstetric and neonatal outcomes in obese diabetic women. BMC Pregnancy Childbirth. 2015;15:249.

34. Harper LM, Tita A, Biggio JR. The institute of medicine guidelines for gestational weight gain after a diagnosis of gestational diabetes and pregnancy outcomes. Am J Perinatol. 2015;32(3):239-46.

35. Friedman JE. Obesity and Gestational Diabetes Mellitus Pathways for Programming in Mouse, Monkey, and Man-Where Do We Go Next? The 2014 Norbert Freinkel Award Lecture. Diabetes Care. 2015;38(8):1402-11. 